\title{
Towards an Interdisciplinary Focus on Sound in Ethnobiology Research
}

\author{
Claire Wright ${ }^{1^{*}}$ \\ ${ }^{1}$ Department of Anthropology and Department of Folklore and Ethnomusicology, Indiana University, Bloomington, USA. \\ *clcwrigh@indiana.edu
}

\begin{abstract}
Research on perception and ecological knowledge in ethnobiology has primarily focused on sight, in tandem with taste, smell, and touch. Sound, however, has been largely neglected as a topical or methodological focus. This review addresses research in ethnomusicology and soundscape ecology to suggest how attention to sound could open new avenues and add value to ethnoecological research.
\end{abstract}

Received September 10, 2016

OPEN ठACCESS

Accepted March 24, 2017

DOI 10.14237/ebl.8.1.2017.788

Keywords Ethnomusicology, Soundscape ecology, Ethnoecology, Methodology, Perception

Copyright (c) 2017 by the author(s); licensee Society of Ethnobiology. This is an open-access article distributed under the terms of the Creative Commons Attribution-NonCommercial 4.0 International Public License (https://creativecommons.org/licenses/by-nc/4.0), which permits non-commercial use, distribution, and reproduction in any medium, provided the original author and source are credited.

Sound is an important element in an individual's understanding of place and environmental conditions. As ethnobiology research has shown, sounds are often used as signals or cues for various events or presences, such as a bird that sings before it rains (Schaffer 2014:315). While there are examples of sounded ecological knowledge within ethnobiology research, it is usually peripheral, especially to methodologies unrelated to linguistics. Considering that very few studies forefront sound, this review discusses several that do and their potential to inform future research.

In addition, this review will argue that a move towards ethnobiology research that directly recognizes sounded ecological knowledge, will benefit greatly by looking at examples of literature outside ethnobiology, especially from ethnomusicology and soundscape ecology. Ethnomusicology has a long history of research into the importance of sound in ecological and social understandings, while soundscape ecology is a new field that "examines how sounds produced by objects over space and time are related to natural and human activities occurring at a place" (Pijanowski 2016:839). Conversation between the three fields of ethnobiology, ethnomusicology, and soundscape ecology have the potential to bridge gaps and develop innovative interdisciplinary methodologies to understand the importance of environmental sound from biological (e.g., animals/humans) and nonbiological (e.g., thunder) sources.
Sound studies have been popular in the social sciences and humanities for decades, but a recent surge in technological advances in audio recording has led to research on sound, from a wholistic as opposed to single species perspective, in the ecological sciences. Soundscape ecology has largely centered on non-human research, such as long-term sound studies evaluating environmental health and investigations of spatial-temporal patterns to ascertain interactions between species (Pijanowski 2016). Ethnomusicologists have led the call for greater integration between sound studies in the social and biological sciences, and focusing more attention to sound, music, and meaning (Guyette and Post 2015). Ethnobiology is in a unique position to link these interdisciplinary sound studies, especially because of its long history of addressing local ecological knowledge and bridging the humanities and biological science disciplines.

Sound can provide information that is crucial and not readily accessible through sight. Whereas soundscape ecologists are now using recorders to monitor environmental health (Pijanowski 2016), ethnobiologists have, for decades, studied communities that use sound as indicators of environmental dynamics (Hunn 1992; Schaffer 2014). Unfortunately, most ethnobiological literature mentioned such data peripherally. The few examples of studies emphasizing sound can serve as an important resource for future research. Ethnobiological research that incorporates sound maybe grouped according to 
several themes. A first such theme includes sound as an environmental indicator. Turpin et al. (2013) write of the importance of sounds made by snake lizards as a signal that yams are ready for harvest. A second theme is language and sound, such as onomatopoeia and sound symbolism. Among the numerous resources in this area, an article by Berlin and O'Neill (1981) illustrates the long history of this theme in ethnobiology research. A third is evident in classification systems research, some of which incorporate all the physical senses. For example, an article by Ramires et al. (2015) describes research incorporating visual and aural methodologies to elicit data from participants.

Hunn (1992) also references ethnobiological methods involving sound. While there are a few examples which incorporate sound into methods, in many cases it is completely absent. For example, a useful and recent methods book entitled Methods of Ethnoecology and Ethnobiology focuses primarily on visual stimuli without any mention of sound in discussions of environmental perception (Albuquerque et al. 2014).

At issue is not ethnobiology's heavy focus on visual stimuli, which makes sense considering that many animal species and plants are non-vocal. Instead, the concern is over the dearth of research focusing on sound from biological and/or nonbiological sources. The few studies addressing sound as a primary topic illustrate its potential benefits. For example, Jennifer Schine (2012) wrote about "acoustical ecologies of knowing the biological world through sonic interactions with ethnobiology," arguing that "our experience of listening can inform us about the transformation (and continuity) of resource-based living to environmentalism, and the contemporary importance of sound in the cultural history of British Columbia's coastal communities." In another unique example, Firew Mekbib looked at folksongs in a farming community in Ethiopia, arguing that they are used to transmit knowledge about caring for sorghum, the main crop. The author called this research a "new system of appraising farmers' bioecocultural heritage" (Mekbib 2009:1).

Outside of ethnobiology, other fields with lengthy durée in sound focused research could serve as important resources to encourage innovative research and methodologies. Collaboration between ethnomusicology, ethnobiology, and soundscape ecology could improve methodologies for understanding ecological knowledge, its importance, and the ways in which communities are adapting to climate and environmental change more broadly. Many ethnomusicologists have studied local ecological knowledge, looking at the importance of sound in ecological knowledge and cultural identity for decades (e.g., Feld 2012; Seeger 1981). More recent articles on sounded knowledge have looked at the role of sound and agency, space, and human-non-human relationships (e.g., de Mori and Seeger 2013; Sakakeeny 2010). In addition, Guyette and Post (2015) have already begun to bridge soundscape ecology and ethnomusicology. Their article looked at two case studies in Mongolia and New Zealand, presenting research from a soundscape ecological perspective and an ethnomusicological perspective for each.

Soundscape ecology and ethnobiology also stand to benefit from consulting one another's literature. Shaffer's (2014) article on co-producing climate knowledge between community members in Rural Tanzania and Western scientists serves as an example of possible intersections between these two fields. While the article is focused on visual markers, she opens with a quote from a community elder about changing climate causing birds to no longer make certain calls used to predict the weather (Shaffer 2014:315). This article illustrates that, peripherally, published ethnobiological studies point to the importance of sound for communities' perceptions of climate change, which soundscape ecologists are just starting to detect in their analysis (Krause and Farina 2016). The inclusion of soundscape ecology's methods of passive acoustic recording and analysis could contribute to the co-production of knowledge between researchers and collaborators. Potentially useful analyses include tracking specific species over time (of interest to collaborators), and looking for overall patterns and changes in the make-up of sounds throughout days, seasons, and even years (Pijanowski 2016).

\section{Acknowledgements}

I am especially grateful to Eduardo Brondizio for his encouragement and guidance, as well as the anonymous reviewers for their insightful and constructive feedback.

\section{Declarations}

Permissions: None declared.

Sources of funding: None declared.

Conflicts of Interest: None declared. 


\section{References Cited}

Albuquerque, U. P., L. V. F. Cruz, R. F. P. Lucena, and R. R. N. Alves, eds. 2014. Methods and Technique in Ethnobiology and Ethnoecology. Springer, New York, NY.

Berlin, B., and J. P. O’Neill. 1981. The Persuasiveness of Onomatopoeia in Aguaruna and Huambisa Bird Names. Journal of Ethnobiology 1:238-261. Available at: http:/ /www.botanicus.org/ item/31753002401393\#. Accessed on January 17, 2017.

de Mori, B. B., and A. Seeger. 2013. Introduction: Considering Music, Humans, and Non-humans. Ethnomusicology Forum 22:269-286.

Feld, S. 2012. Sound and Sentiment: Birds, Weeping, Poetics, and Song in Kaluli Expression, $3^{\text {rd }}$ edition. Duke University Press, Durham, NC.

Guyette, M. Q., and J. C. Post. 2015. Ecomusicology, Ethnomusicology, and Soundscape Ecology: Scientific and Musical Responses to Sound Study. In Current Directions in Ecomusicology, edited by A. S. Allen and K. Dawe, pp. 40-65. Routledge, New York, NY.

Hunn, E. 1992. The Use of Sound Recordings as Voucher Specimens and Stimulus Materials in Ethnozoological Research. Journal of Ethnobiology 12:187-198. Available at: http:// www.botanicus.org/page/1760570. Accessed on March 28, 2016.

Krause, B., and A. Farina. 2016. Using Ecoacoustic Methods to Survey the Impacts of Climate Change on Biodiversity. Biological Conservation 195:245-254. DOI:10.1016/j.biocon.2016.01.013.

Mekbib, F. 2009. Folksong Based Appraisal of Bioecocultural Heritage of Sorghum (Sorghum bicolor (L.) Moench): A New Approach in Ethnobiology. Journal of Ethnobiology and Ethnomedicine 5:19. DOI:10.1186/1746-4269-5-19.

Pijanowski, B. C. 2016. Terrestrial Soundscape: Status of Ecological Research in Natural and HumanDominated Landscapes. In The Effects of Noise on Aquatic Life II, edited by A. N. Popper and A. Hawkins, pp. 839-846. Springer, New York, NY.

Ramires, M., M. Clauzet, W. Barrella, M. M. Rotundo, R. A. M. Silvano, and A. Begossi. 2015. Fishers' Knowledge about Fish Trophic Interactions in the Southeastern Brazilian Coast. Journal of Ethnobiology and Ethnomedicine 11:19. DOI:10.1186/s13002-0150012-8.

Sakakeeny, M. 2010. 'Under the Bridge': An Orientation to Soundscapes in New Orleans. Ethnomusicology 54:1-27. DOI:10.5406/ ethnomusicology.54.1.0001.

Schaffer, L. J. 2014. Making Sense of Local Climate Change in Rural Tanzania Through Knowledge Co -Production. Journal of Ethnobiology 34:315-334. DOI: $10.2993 / 0278-0771-34.3 .315$.

Schine, J. 2012. Soundwalking: Ways of Listening to the Biological World [webpage]. Available at: www.ethnobiology.net/schine-2012congress. Accessed on September 6, 2016.

Seeger, A. 1981. Nature and Society in Central Brazil: The Suyá Indians of Mato Grosso. Harvard University Press, Cambridge, MA.

Turpin, M., A. Ross, V. Dobson, and M. K. Turner. 2013. The Spotted Nightjar Calls When Dingo Pups Are Born: Ecological and Social Indicators in Central Australia. Journal of Ethnobiology 33:7-32. DOI:10.2993/0278-0771-33.1.7. 